\title{
The moderating effect of psychosocial factors in the relation between neighborhood walkability and children's physical activity
}

Sara D'Haese ${ }^{1,2}$, Freja Gheysen ${ }^{1}$, Ilse De Bourdeaudhuij ${ }^{1}$, Benedicte Deforche ${ }^{3,4}$, Delfien Van Dyck ${ }^{1,2^{*}}$ and Greet Cardon ${ }^{1 *}$

\begin{abstract}
Background: The study aimed to investigate if psychosocial factors moderate the association between objective walkability and different domains of children's physical activity (PA). A second aim of the study was to investigate the direct associations between psychosocial factors and children's PA. Based on previous literature, it was hypothesized that walkability would be more strongly related to PA among children with negative psychosocial profiles.

Methods: Data were collected between December 2011 and May 2013 as part of the Belgian Environmental Physical Activity Study in children (BEPAS-child). In total, data from 494 children and one of their parents were included in the study. Children wore an accelerometer for 7 consecutive days and together with one of their parents, they completed the Flemish Physical Activity Questionnaire. Parents filled out a questionnaire concerning their child's psychosocial factors toward PA (i.e. parental attitude toward their child's PA, parental social norm toward their child's PA, parental support, friend support, children's self-efficacy, and perceived benefits and barriers toward sports and PA). Neighborhood walkability was calculated using geographical information systems (GIS). Multilevel cross-classified analyses were conducted.

Results: Of the 42 investigated interactions between neighborhood walkability and psychosocial factors in relation to PA among children, only 7 significant interactions were found of which 3 were only significant among children from low-income neighborhoods.

Parental support and self-efficacy were positive correlates of children's PA in high- and low-income neighborhoods independent of the level of walkability, but effect sizes were small.

Conclusions: The hypothesis that walkability would be more strongly related to PA among children with negative psychosocial profiles could not be confirmed and in general, psychosocial factors and objective walkability did not interact in relation to children's PA. Focusing on parental support and self-efficacy towards PA can possibly cause small effects on children's PA in both high- and low-walkable neighborhoods, as well as in high- and low-income neighborhoods.
\end{abstract}

Keywords: Child, Neighborhood, Psychosocial, Interactions, Physical activity

\footnotetext{
* Correspondence: Delfien.vandyck@ugent.be; greet.cardon@ugent.be

${ }^{1}$ Faculty of Medicine and Health Sciences, Department of Movement and

Sports Sciences, Ghent University, Watersportlaan 2, 9000 Ghent, Belgium

Full list of author information is available at the end of the article
} 


\section{Background}

Despite the numerous health benefits of being sufficiently physically active during childhood [1], many children do not meet the PA guidelines of engaging daily in 60 min of moderate- to vigorous-intensity physical activity (MVPA) [2]. Therefore, it is necessary to obtain insight into physical activity (=PA) determinants among children. When the PA determinants are identified, focusing on these factors in future interventions may result in increased PA levels among children [3]. Ecological models state that PA can be explained by individual (e.g. psychological factors) as well as environmental (e.g. neighborhood characteristics, social environment) factors [4]. To date, the direct association between psychosocial factors (e.g. parental support), the neighborhood environment (e.g. walkability) and children's PA has been thoroughly investigated [5-11].

In review studies, self-efficacy, parental PA (for boys), and parental support [10] were positively associated and perceived barriers toward PA [11] were negatively associated with children's PA. On the other hand, the association between objective neighborhood walkability (characterized by residential density, street connectivity and land use mix diversity [12]) and children's PA is less univocal [5, 13-17]. In a Belgian study with the current 9- to 12-year-old study sample, objective walkability was positively related to walking for transportation during leisure and was negatively related to sports during leisure only in low-income neighborhoods [17]. Further, no direct associations were found between objective walkability and active transportation to school (=ATS), cycling for transportation during leisure and objective MVPA on weekend- and weekdays [17]. Thus, in contrast to adult studies, in which higher walkability has been consistently related to more PA [18-21], only few direct associations between objective walkability and children's PA were found and these associations were dependent on the domain of PA.

According to ecological models, it is likely that factors at different levels (e.g. walkability at the environmental level and psychological factors at the individual level) of the ecological model for PA interact with each other [4]. For example, it is possible that high walkability is related to more cycling for transportation during leisure, only among children with negative psychosocial profiles toward PA and that cycling levels among children with positive psychosocial factors are high, irrespective of their neighborhood walkability. However, the ecological model for PA does not specify which interactions between which factors can be expected or which interactions are most important to explain children's PA [4]. Therefore, it is important to investigate which interactions exist between objective walkability and several psychosocial factors in relation to different domains of children's PA. Several interactions between psychosocial factors and walkability in relation to PA were already identified among adolescents [22], adults [23, 24] and older adults $[25,26]$. Among Belgian adolescents, it was found that in low-income neighborhoods, neighborhood walkability was positively associated with PA among adolescents who perceived many barriers and few benefits, while for adolescents who perceived few barriers and many benefits, the PA level was high, irrespective of neighborhood walkability [22]. Among Belgian adults, it was found that living in a high walkable neighborhood was associated with taking more steps, especially among adults with a preference for passive transport and/or a low intention to walk or cycle [24]. Among Belgian older adults walkability was positively associated with recreational walking in those with high self-efficacy [26]. However, to our knowledge, these interactions were not investigated among children yet. More insight into how neighborhood walkability and different psychosocial characteristics interact in relation to children's PA, can help to identify groups in need of targeted interventions and to develop effective interventions to increase children's PA.

Therefore, the aim of this study was to investigate if psychosocial factors moderate the association between walkability and different domains of children's PA. Based on the results of previous studies among adolescents and adults, it was hypothesized that walkability would be more strongly related to children's PA when children have a negative psychosocial profile (e.g. children who perceive many barriers and few benefits) toward PA, whereas children with more positive psychosocial factors engage in high levels of PA, irrespective of their neighborhood walkability. More specifically, based on previous research among children [17], positive associations are expected between walkability and active transportation to school, walking and cycling for transportation during leisure and MVPA on week- and weekend days among children with negative psychosocial profiles. Negative associations are expected between walkability and sports during leisure, among children with negative psychosocial profiles. Among children with more positive psychosocial profiles, it is expected that walkability is less important to explain their PA. As in previous analyses, walkability was only associated to PA among children living in low-income neighborhoods, analyses were stratified for low- and high-income neighborhoods when a significant three-way interaction between walkability, neighborhood income and psychosocial factors was found in relation to PA.

A second aim of this study was to describe the main effects of psychosocial factors in relation to different domains of children's PA. It was hypothesized that having a more positive psychosocial profile toward PA would be related to more PA among children. 


\section{Methods}

\section{Procedure}

Data were collected between December 2011 and May 2013 as part of the Belgian Environmental Physical Activity Study in children (BEPAS-child). Principals $(n=46)$ from primary schools in Ghent (237000 inhabitants, $15685 \mathrm{~km}^{2}$ ) were asked to participate. In total, 18 (34.6\%) agreed and gave written informed consent. All children and their parents from fourth, fifth and sixth grade $(n=$ 994) were informed about the study and 606 parents (61.0\%) gave written informed consent. Due to practical limitations, objective walkability data were only collected for children living in Ghent. Therefore, of these 606 children who participated, 112 children were excluded as no objective walkability data were available (69 children did not live in Ghent and 43 parents did not fill out children's home address in the questionnaire). This resulted in a final sample of 494, 9- to 12-year-old children (Fig. 1).

Children were asked to wear an accelerometer for 7 consecutive days, to fill out a questionnaire at school and one of the parents was asked to fill out a questionnaire together with his/her child. The Ethics Committee of the Ghent University Hospital approved the study.

\section{Measurements}

\section{Demographic variables}

Sex was derived from children's questionnaire and children's age from the parental questionnaire. Educational attainment of both parents was used as a proxy for family socio-economic status (SES). Parents were asked to report their level of education (response options: primary school education, vocational, technical, general or art secondary education, college education or university education). Families were classified as high SES families if the educational level of at least one parent was of a college or university education level; otherwise they were classified as low/medium SES families. Educational attainment was used as a proxy for family SES, as educational attainment is easy to measure and is fairly stable in early adulthood, and higher levels of education are usually associated with better jobs, housing, neighborhoods, working conditions and higher incomes [27] which are usually related to higher SES.

\section{Physical activity}

PA was measured using two complementary methods: accelerometry and questionnaires. These methods are not interchangeably as they are not assessing the same thing [28]. Accelerometry was used to determine children's overall PA in an objective way by measuring accelerations of the body. The Flemish Physical Activity Questionnaire was used to determine PA among children in different contexts.

Objective MVPA was determined by accelerometers. Children wore an Actigraph ${ }^{\mathrm{TM}}$ GT1M, GT3X or GT3X+ accelerometer (15 s epoch) during waking hours for 7 consecutive days. Strong agreement was found between these activity monitors for measuring children's MVPA [29], making it acceptable to use different models within a given study. The accelerometer was worn on the right hip. Accelerometer data were screened, cleaned and scored using data-reduction software MeterPlus 4.2. Periods of 20 min of consecutive zeros or more were removed and defined as non-wear time [30, 31]. Non-wear time activity diaries were provided to register activities for which the accelerometer was removed and were used to replace the consecutive number of zeros by the corrected minutes MVPA [32]. MVPA was calculated using

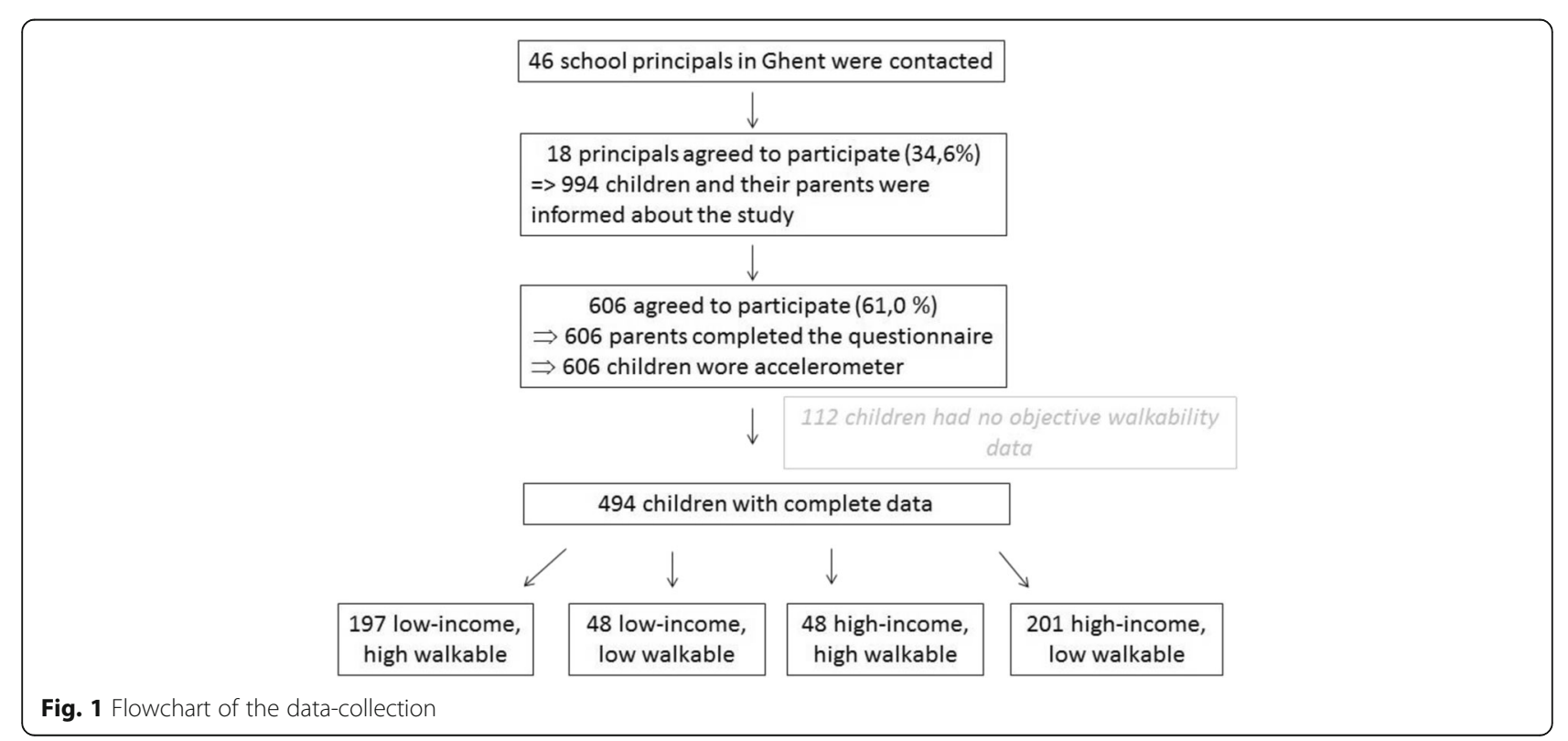


the cutpoints of Evenson ( $>2296$ counts per minute was defined as MVPA), as these cutpoints were recommended in a comparative validity study [33, 34]. Children were included in the study if they had at least 2 weekdays with minimum $10 \mathrm{~h}$ wear time or 1 weekend day with minimum $8 \mathrm{~h}$ wear time [35].

Children's reported PA was assessed with the Flemish Physical Activity Questionnaire (FPAQ). Parents were asked to fill out the questionnaire at home together with their child and to report their child's PA levels in a usual week. This questionnaire has been shown to be a reliable and reasonably valid instrument to assess different dimensions of PA in children, especially when completed with parental assistance [36]. The number of minutes per day of walking and cycling for transport during leisure, ATS and sports during leisure were derived from the questionnaire.

\section{Neighborhood variables}

Neighborhood income Ghent consists of 201 statistical sectors (the smallest administrative entities for which statistical data are available). Median annual household income data (National Institute of Statistics-Belgium, 2008) were used to determine neighborhood income of the different statistical sectors. Neighborhoods were characterized as low-income (income $<€ 22,359$ ) or highincome (income $\geq € 22,359$ ) neighborhoods based on the median.

Walkability Objective neighborhood walkability was calculated using a geographical information system (GIS) database. Geographical data were obtained from the Service for Environmental Planning in Ghent in 2012.

Residential density, intersection density and land use mix diversity of each neighborhood (i.e. statistical sector) were determined and $\mathrm{z}$-scores were calculated. Walkability was calculated as follows: walkability $=\left(2^{*} z\right.$-connectivity) + (z-residential density) + (z-land use mix). Because no data of 'retail floor area' were available, this was omitted from the original formula of Frank and colleagues [37]. Residential density was calculated using the ratio of residential units to the land area devoted to residential use. Connectivity was represented by the ratio of the number of intersections ( 3 or more streets) to the land area. Land use mix indicated the degree of diversity of land use types. Five land use types were considered: residential, retail, office, institutional, and recreational. Neighborhoods were characterized as low walkable or high walkable, based on the median.

\section{Psychosocial factors}

Parental attitude toward their child's PA, parental social norm toward their child's PA, parental support, friend support, and self-efficacy, perceived benefits and barriers toward sports and PA were parental reported, as parents are often seen as the main decision makers for their child. Questions were answered from parents' viewpoint, concerning children's psychosocial factors. Questions to assess psychosocial factors were derived from previous studies among adults and adolescents [22, 38-42]. These psychosocial factors were derived from the ASE-model by De Vries et al. [43]. The predictive validity and reliability of these items has been demonstrated previously among adolescents and adults [44, 45]. Table 1 gives an overview of the content and response options of the psychosocial factors. The scores (range 1-5) on the different items per factor were summed, with a higher score representing better psychosocial factors toward PA. Cronbach Alpha's ranged from 0.71 until 0.85 . No reliability data were available for these factors measuring children's psychosocial characteristics reported by their parents.

\section{Analyses}

Descriptive characteristics of the sample were analyzed using SPSS20. PA variables were logarithmically transformed to improve normality. After the transformation, skewness values were lower than $|0.7|$ for al PA variables, except for walking for transportation during leisure (skewness -0.844). Linear regression analyses were conducted in MLwiN2.32. Multilevel modeling was used to take into account clustering of children within classes within schools; and schools, classes and neighborhoods were treated as cross-classified. Model parameter estimates were obtained via Markov Chain Monte Carlo procedures applying an orthogonal parameterization [46]. Before multilevel regression analyses were conducted, multicollinearity within psychosocial factors was checked by conducting Pearson's correlations in SPSS20. The magnitude of the correlation coefficients did not exceed 0.60 , indicating that multicollinearity was not present. Given that the association between neighborhood walkability and children's may differ between lowversus high-income neighborhoods [17], preliminary analyses, examining three-way interactions between neighborhood walkability, neighborhood income and psychosocial factors were conducted for the different outcome measures. Significant three-way interactions were found in relation to active transportation to school and MVPA on weekend days. Therefore, the sample was stratified according to high- and low-income neighborhoods when these outcome measurements were investigated.

All psychosocial variables were centered around their mean and analyses were conducted in two consecutive steps. In a first step, for each PA measure, moderating (cross-product term of walkability and 
Table 1 Content and response options of the psychosocial factors

\begin{tabular}{|c|c|c|}
\hline & Content of the items & Response options \\
\hline $\begin{array}{l}\text { Parental attitude toward their child's physical activity } \\
\text { (1 item) }\end{array}$ & $\begin{array}{l}\text { I think that being physically active and doings } \\
\text { sports for my child is: }\end{array}$ & $\begin{array}{l}\text { very unimportant }(=1) \text {, unimportant }(=2) \text {, } \\
\text { sometimes important/sometimes unimportant } \\
(=3) \text {, important }(=4) \text {, very important }(=5)\end{array}$ \\
\hline $\begin{array}{l}\text { Parental support } \\
(6 \text { items: Cronbach Alpha }=0.772)\end{array}$ & $\begin{array}{l}\text { How frequently ... } \\
\text {-... do you encourage your child to be active } \\
\text { and do sports? } \\
\text {-... are you physically active or doing sports } \\
\text { together with your child? } \\
\text {-...do you bring your child to the place } \\
\text { where he/she sports, are you going to watch } \\
\text { or support? } \\
\text {-... are you watching or cheering your child } \\
\text { while he/she sports? } \\
\text {-... do you offer your child to be physically } \\
\text { active together? } \\
\text {-...do you say your child is doing well? }\end{array}$ & $\begin{array}{l}\text { Never }(=1) \text {, seldom }(=2) \text {, sometimes }(=3) \\
\text { often }(=4) \text {, very often }(=5)\end{array}$ \\
\hline $\begin{array}{l}\text { Friend support } \\
\text { (1 item) }\end{array}$ & $\begin{array}{l}\text { How frequently are your child's friends or } \\
\text { siblings physically active together with your } \\
\text { child? }\end{array}$ & $\begin{array}{l}\text { Never }(=1) \text {, seldom }(=2) \text {, sometimes }(=3) \text {, } \\
\text { often }(=4) \text {, very often }(=5)\end{array}$ \\
\hline $\begin{array}{l}\text { Parental social norm toward their child's physical } \\
\text { activity } \\
\text { (1 item) }\end{array}$ & $\begin{array}{l}\text { I think my child has to engage regularly in } \\
\text { physical activity. }\end{array}$ & $\begin{array}{l}\text { strongly disagree }(=1) \text {, somewhat disagree } \\
(=2) \text {, neither agree or disagree }(=3) \text {, somewhat } \\
\text { agree }(=4) \text {, strongly agree }(=5)\end{array}$ \\
\hline $\begin{array}{l}\text { Self-efficacy } \\
\text { ( } 4 \text { items: Cronbach Alpha }=0.849 \text { ) }\end{array}$ & $\begin{array}{l}\text { I am sure my child will be physically active } \\
\text { even if... } \\
-\ldots \text { he/she has to get up early. } \\
-\ldots \text { his/her friends want to do something else. } \\
-\ldots \text { he/she has a lot of work for school } \\
-\ldots \text { it is exhausting and difficult. }\end{array}$ & \\
\hline $\begin{array}{l}\text { Benefits } \\
\text { (6 items: Cronbach Alpha }=0.713 \text { ) }\end{array}$ & $\begin{array}{l}\text { My child believes that being physically active } \\
\text { and doing sports is important because... } \\
-\ldots \text { his/her condition and health will improve. } \\
-\ldots \text { he/she get in contact with (new) friends } \\
-\ldots \text { he/she enjoys being physically active } \\
-\ldots \text { he/she can show that he/she is better } \\
\text { than others } \\
\text {-... he/she does not get bored if he/she is } \\
\text { physically active } \\
-\ldots \text { he/she lose weight and his/her body } \\
\text { becomes more beautiful }\end{array}$ & \\
\hline $\begin{array}{l}\text { Barriers } \\
\text { ( } 8 \text { items: Cronbach Alpha }=0.801)\end{array}$ & $\begin{array}{l}\text { My child cannot be engaged in sports... } \\
-\ldots \text { due to lack of time. } \\
-\ldots \text { because he/she does not enjoy sports. } \\
-\ldots \text { because he/she is not good in doing } \\
\text { sports. } \\
\text {... because he/she does not always have } \\
\text { transport to activities. } \\
\text {-... because he/she is not allowed by his/her } \\
\text { parents. } \\
\text {.... because there are no sport facilities in our } \\
\text { neighborhood. } \\
\text {.... because it is too expensive. } \\
\text { f... because there is nobody (no friends or } \\
\text { family) who wants to accompany my child. }\end{array}$ & \\
\hline
\end{tabular}

each psychosocial factor) and main effects were calculated separately for each psychosocial variable and walkability. In a second step, a multivariable model was built, including all main and interaction terms yielding $p<0.10$ in the first step. All analyses were controlled for accelerometer wear time (if relevant), family SES, sex and age of the child.
Because regression coefficients represented relationships with logarithmically transformed PA variables, predicted weekly minutes of PA were calculated from MLwiN's customized prediction window [47]. The predicted values were calculated with all covariates fixed at their mean. To visualize moderating effects, the predicted PA measure was plotted against the mean -1 
standard deviation and the mean +1 standard deviation of the corresponding psychosocial variable at low and high walkability.

Local effect sizes of the interaction terms and significant terms were determined by calculating Cohen's $\mathrm{f}^{2}$ effect sizes, which is an effect size measure to use in the context of multiple regression [48]. Cohen's $\mathrm{f}^{2}$ effect sizes lower than 0.02 were considered very small, values between 0.02 and 0.15 are considered small, effect sizes between 0.15 and 0.35 are considered moderate and effect sizes larger than 0.35 are considered large [49].

$P<0.05$ was considered as significant with exception for the interaction terms were it was set at $p<0.10$ [50].

\section{Results}

\section{Descriptive characteristics}

In total, $45.1 \%$ of the children were boys and $37.1 \%$ had low family SES and the mean age was $10.9 \pm 0.9$ years. Parental reported psychosocial characteristics toward PA were generally high (Table 2).

\section{Interactions between psychosocial factors and objective walkability in relation to PA}

An overview of the bivariate interaction- and main effects of psychosocial factors and walkability in relation to PA is given Table 3. The multivariate associations are presented in Table 4 and are described below.

\section{Active transportation to school}

In low-income neighborhoods, parental attitude toward PA and walkability interacted in relation to active transportation to school $(\beta=-0.351 \pm 0.150, \quad p=0.019$; Cohen's $\mathrm{f}^{2}=0.02$; Fig. 2a). For children with low parental reported attitude, high vs. low walkability accounted for 1.80 additional $\mathrm{min} /$ day of walking for transportation during leisure. For children with high parental reported self-efficacy, high versus low walkability accounted for 0.10 additional $\mathrm{min} /$ day of walking for transportation during leisure.

In high income neighborhoods, no significant interaction effects and no significant associations of psychosocial factors and objective walkability with ATS were found (Table 4).

\section{Walking for transportation during leisure}

A moderating effect of parental reported self-efficacy was found in the relation between objective walkability and walking for transportation during leisure $(\beta=0.093$ $\pm 0.054, p=0.065$; Cohen's $f^{2}<0.001$; Fig. $\left.2 b\right)$. For children with low parental reported self-efficacy, high vs. low walkability accounted for 1.50 additional min/day of walking for transportation during leisure. For children

Table 2 Descriptive characteristics of the sample

\begin{tabular}{|c|c|c|c|c|c|}
\hline & \multirow[t]{2}{*}{ Overall } & \multicolumn{2}{|c|}{ Low-income neighborhoods } & \multicolumn{2}{|c|}{ High-income neighborhoods } \\
\hline & & High walkable & Low walkable & High walkable & Low walkable \\
\hline N & 494 & 197 & 48 & 48 & 201 \\
\hline Sex (\% boys) & 45.1 & 46.7 & 50.0 & 45.8 & 42.3 \\
\hline Age (years) & $10.93 \pm 0.90$ & $11.02 \pm 0.93$ & $10.96 \pm 0.95$ & $11.01 \pm 0.90$ & $10.81 \pm 0.86$ \\
\hline Family SES (\% low SES) & 37.1 & 51.1 & 42.6 & 20.8 & 26.4 \\
\hline \multicolumn{6}{|l|}{ Psychosocial factors (mean \pm SD) } \\
\hline Parental attitude (/5) & $4.46 \pm 0.64$ & $4.36 \pm 0.70$ & $4.54 \pm 0.58$ & $4.50 \pm 0.55$ & $4.52 \pm 0.61$ \\
\hline Parental support (/5) & $3.54 \pm 0.74$ & $3.39 \pm 0.84$ & $3.59 \pm 0.67$ & $3.71 \pm 0.65$ & $3.64 \pm 0.66$ \\
\hline Friend support (/5) & $3.54 \pm 1.02$ & $3.40 \pm 1.04$ & $3.60 \pm 1.12$ & $3.41 \pm 1.07$ & $3.69 \pm 0.94$ \\
\hline Parental social norm (/5) & $4.48 \pm 0.76$ & $4.29 \pm 0.92$ & $4.63 \pm 0.53$ & $4.59 \pm 0.62$ & $4.59 \pm 0.63$ \\
\hline Self-efficacy (/5) & $3.39 \pm 0.93$ & $3.31 \pm 0.95$ & $3.39 \pm 0.87$ & $3.45 \pm 0.93$ & $3.45 \pm 0.93$ \\
\hline Benefits (/5) & $3.48 \pm 0.68$ & $3.56 \pm 0.74$ & $3.47 \pm 0.64$ & $3.34 \pm 0.73$ & $3.44 \pm 0.62$ \\
\hline Barriers (/5) & $1.83 \pm 0.67$ & $2.01 \pm 0.77$ & $1.83 \pm 0.60$ & $1.70 \pm 0.51$ & $1.71 \pm 0.60$ \\
\hline \multicolumn{6}{|l|}{ Physical activity [17] (mean \pm SD, mins/day) } \\
\hline Active transportation to school $(n=483)$ & $5.1 \pm 7.7$ & $5.7 \pm 8.6$ & $3.7 \pm 6.3$ & $4.8 \pm 8.8$ & $4.8 \pm 7.2$ \\
\hline Walking for transportation during leisure $(n=484)$ & $6.6 \pm 11.6$ & $11.3 \pm 14.0$ & $3.5 \pm 7.9$ & $4.6 \pm 9.3$ & $3.3 \pm 8.1$ \\
\hline Cycling for transportation during leisure $(n=485)$ & $4.7 \pm 9.1$ & $5.0 \pm 9.8$ & $3.9 \pm 5.5$ & $5.3 \pm 10.2$ & $4.6 \pm 8.9$ \\
\hline Sports during leisure $(n=485)$ & $20.2 \pm 20.2$ & $16.2 \pm 19.1$ & $25.4 \pm 24.4$ & $22.1 \pm 18.2$ & $22.4 \pm 20.1$ \\
\hline MVPA weekday $(n=409)$ & $60.2 \pm 23.5$ & $56.0 \pm 23.2$ & $63.6 \pm 19.7$ & $64.2 \pm 24.2$ & $60.3 \pm 24.3$ \\
\hline MVPA weekend day $(n=389)$ & $50.0 \pm 30.6$ & $47.1 \pm 26.8$ & $41.5 \pm 24.1$ & $54.8 \pm 32.8$ & $53.6 \pm 33.9$ \\
\hline
\end{tabular}




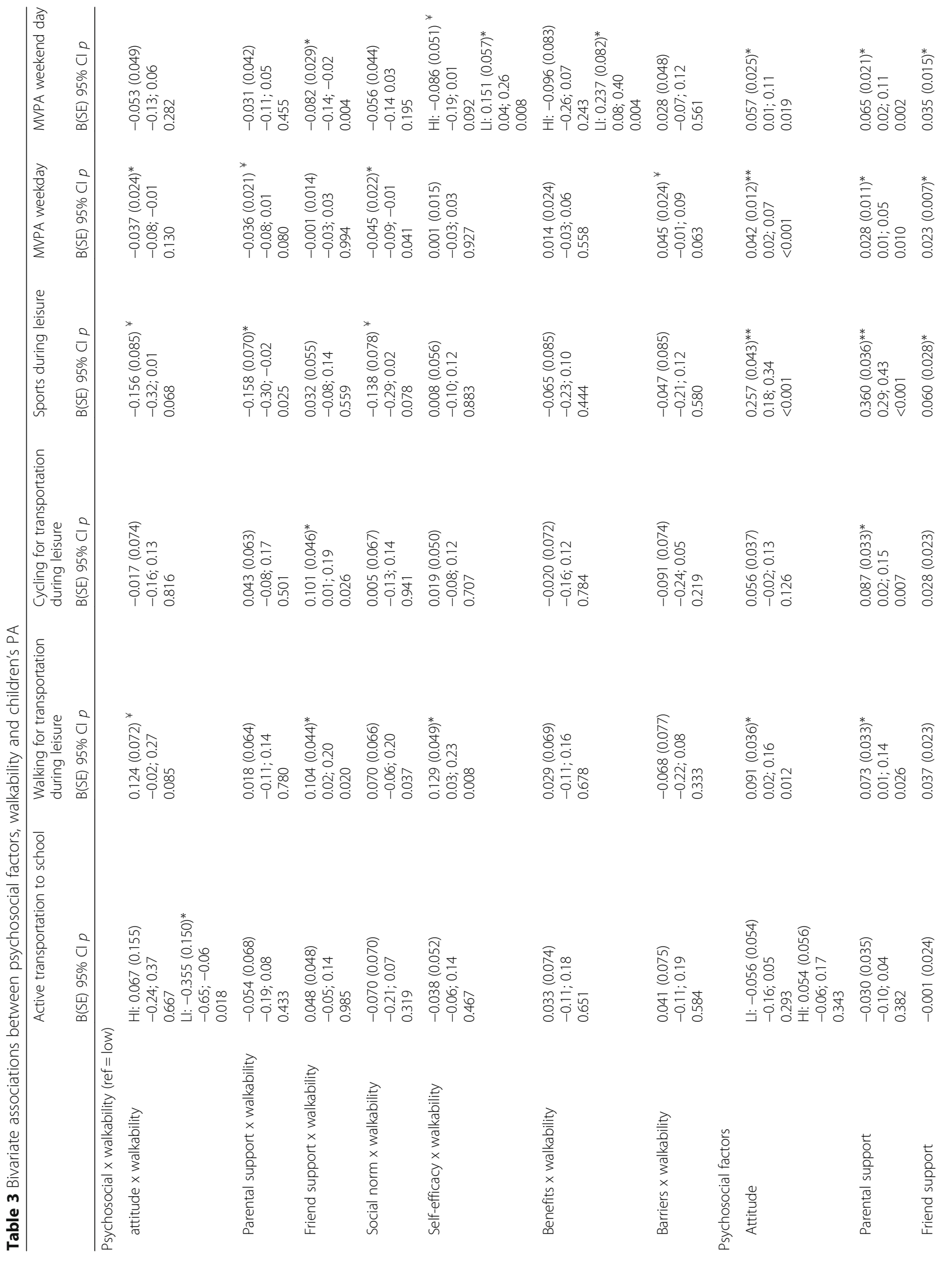




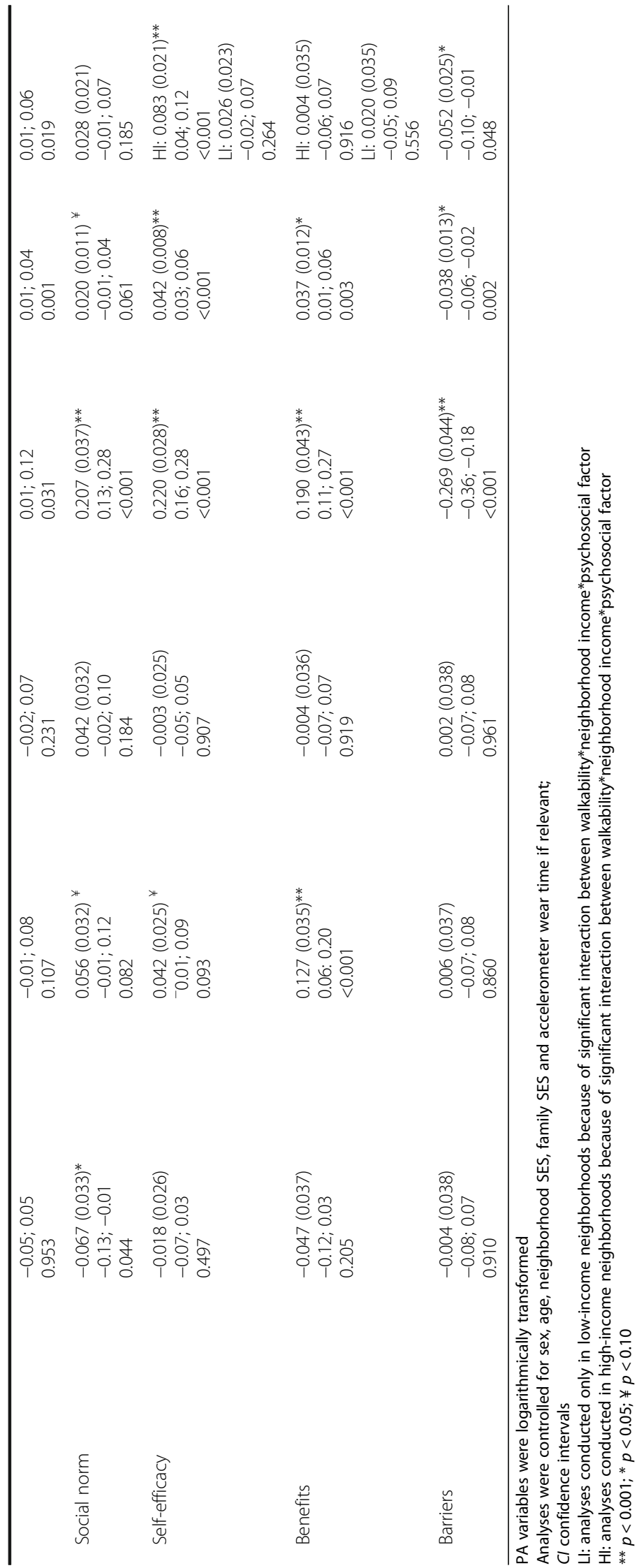




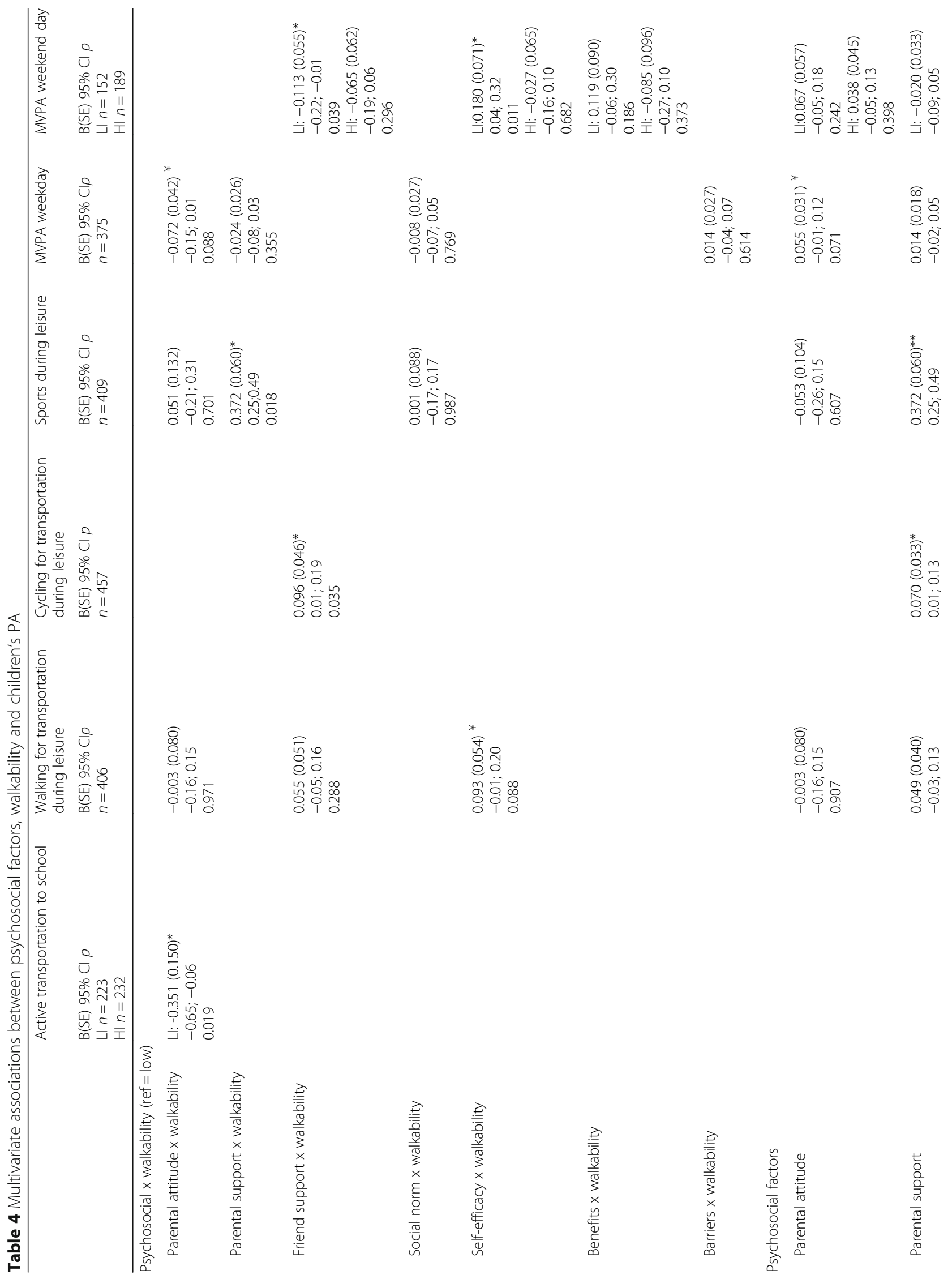


D’Haese et al. International Journal of Behavioral Nutrition and Physical Activity (2016) 13:128

Page 10 of 16

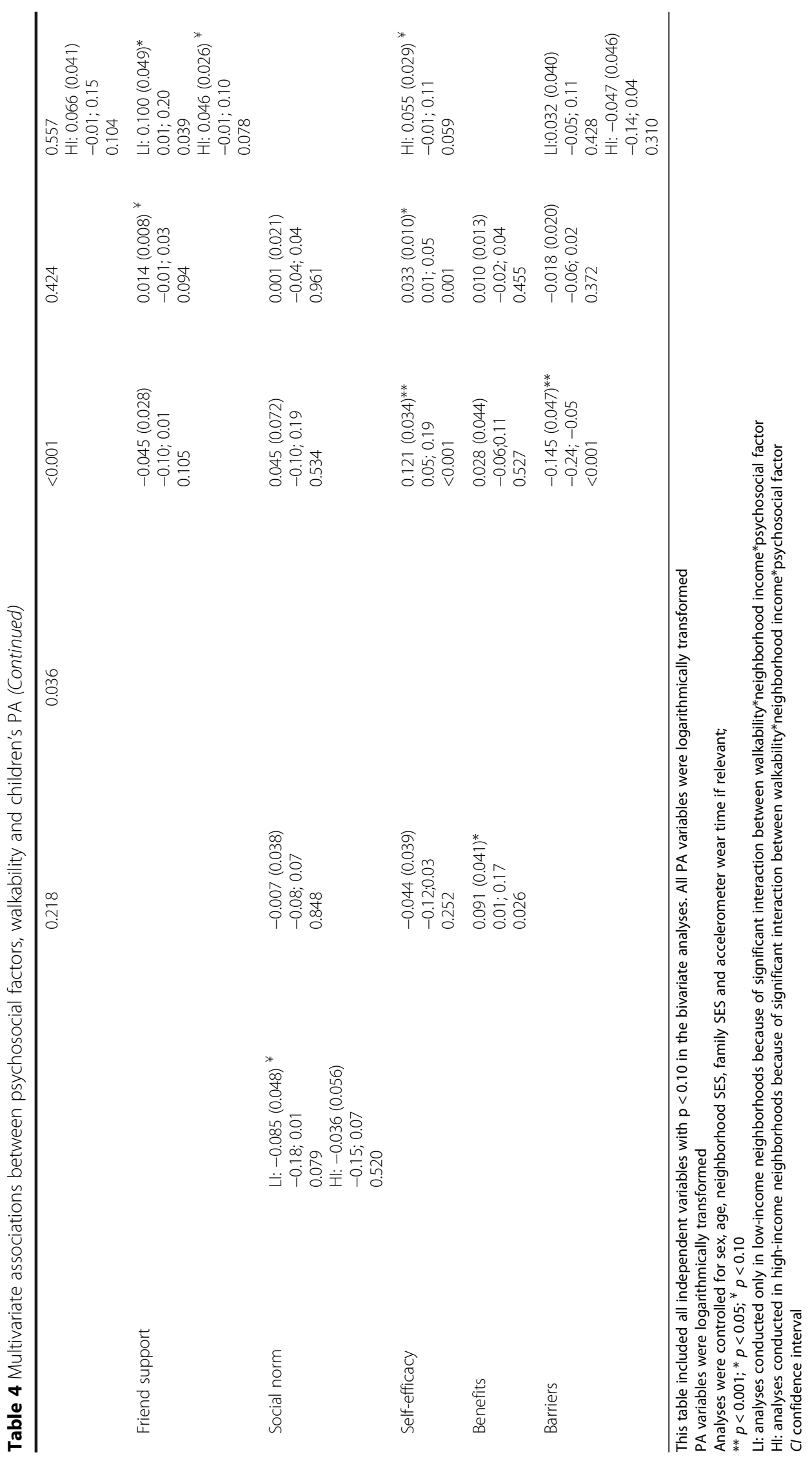




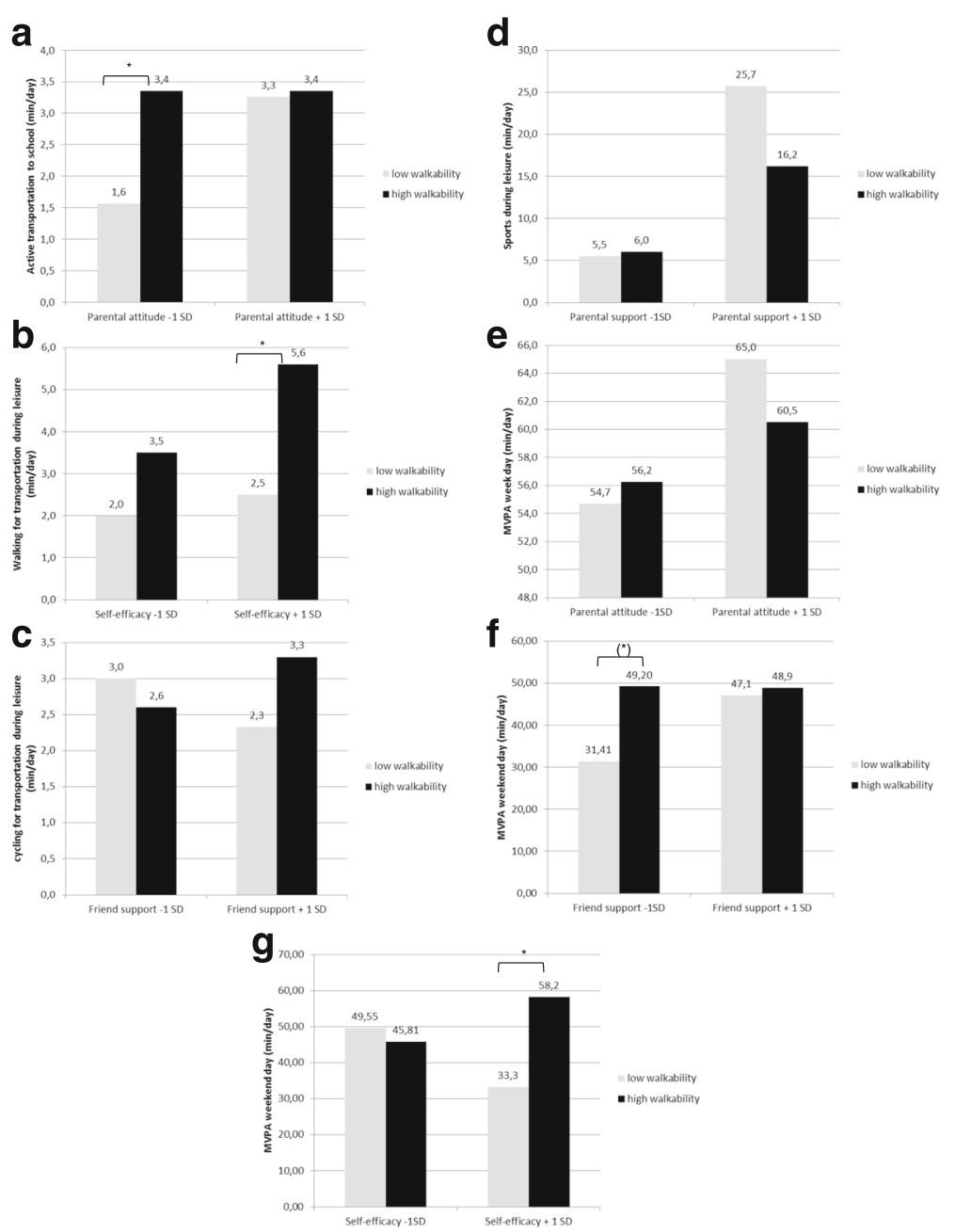

Fig. 2 a Moderating effect of parental attitude in the association between walkability and active transportation to school. b Moderating effect of selfefficacy in the association between walkability and walking for transportation during leisure. c Moderating effect of friend support in the association between walkability and cycling for transportation. $\mathbf{d}$ Moderating effect of parental support in the association between walkability and sports during leisure. e Moderating effect of parental attitude in the association between walkability and MVPA on a weekday. $\mathbf{f}$ Moderating effect of friend support in the associatin between walkability and MVPA on a weekend day. $\mathbf{g}$ Moderating effect of self-efficacy in the assocation between walkability and MVPA on a weekend day

with high parental reported self-efficacy, high versus low walkability accounted for 3.10 additional $\mathrm{min} /$ day of walking for transportation during leisure.

Perceived benefits were positively related to walking for transportation during leisure $(\beta=0.091 \pm 0.041, p=$ 0.026; Cohen's $\mathrm{f}^{2}=0.03$ ) (Table 4).

\section{Cycling for transportation during leisure}

A moderating effect of friend support was found in the relation between walkability and cycling for transportation during leisure ( $\beta=0.096 \pm 0.046, p=0.035$; Cohen's $\mathrm{f}^{2}<0.001$; Fig. 2c). For children with low friend support, high versus low walkability accounted for 0.40 fewer $\mathrm{min} /$ day of cycling for transportation during leisure.
For children with high friend support, high versus low walkability accounted for 1.00 additional min/day of cycling for transportation during leisure.

Parental support was positively related to cycling for transportation during leisure $(\beta=0.070 \pm 0.033, p=0.036$; Cohen's $\left.\mathrm{f}^{2}<0.001\right)$ (Table 4).

\section{Sports during leisure}

A moderating effect of parental support was found in the relation between walkability and sports during leisure $(\beta$ $=0.372 \pm 0.060, p=0.018$; Cohen's $\mathrm{f}^{2}=0.01$; Fig. $2 \mathrm{~d}$ ). For children with low parental support, high versus low walkability accounted for 0.50 additional $\mathrm{min} /$ day of sports during leisure. For children with high parental support, 
high versus low walkability accounted for 9.50 fewer min/ day of sports during leisure.

Positive associations were found of parental reported parental support $\left(\beta=0.372 \pm 0.060, p<0.001\right.$; Cohen's $f^{2}$ $=0.10)$, and self-efficacy $(\beta=0.121 \pm 0.034, \quad p<0.001$; Cohen's $f^{2}=0.04$ ) with sports during leisure. A negative association was found between parental reported barriers and sports during leisure $(\beta=-0.145 \pm 0.047, p=$ 0.002; Cohen's $\mathrm{f}^{2}=0.02$ ) (Table 4).

\section{Objectively measured weekday MVPA}

A moderating effect of parental attitude was found in the relation between walkability and MVPA on weekdays $\left(\beta=-0.072 \pm 0.042, p=0.088\right.$; Cohen's $\mathrm{f}^{2}<0.001$; Fig. $\left.2 \mathrm{e}\right)$. For children with low parental attitude, high versus low walkability accounted for 1.5 additional min/day of MVPA on weekdays. For children with high parental support, high versus low walkability accounted for 4.50 fewer min/day of MVPA on weekdays.

Self-efficacy $\left(\beta=0.033 \pm 0.010, p<0.001\right.$; Cohen's $\mathrm{f}^{2}<$ 0.001 ) was positively related to MVPA on weekdays (Table 4).

\section{Objectively measured weekend day MVPA}

In low-income neighborhoods, a moderating effect of parental reported friend support was found in the relation between walkability and MVPA on weekend days $\left(\beta=-0.106 \pm 0.054, p=0.039\right.$; Cohen's $f^{2}=0.04$; Fig. 2 f $)$. For children with low friend support, high versus low walkability accounted for 17.79 additional minutes MVPA/weekend day. For children with high friend support, high versus low walkability accounted for 1.77 more minutes MVPA/weekend day. In addition, a moderating effect of parental reported self-efficacy was found in the relation between walkability and MVPA on weekend days $\left(\beta=0.180 \pm 0.071, p=0.011\right.$; Cohen's $\mathrm{f}^{2}=0.04$; Fig. $2 \mathrm{~g}$ ) in low-income neighborhoods. For children with lower self-efficacy, high versus low walkability accounted for 3.74 fewer minutes MVPA/weekend day. For children with higher self-efficacy, high versus low walkability accounted for 24.29 more minutes MVPA/weekend day. Friend support was positively related to weekend MVPA $\left(\beta=0.100 \pm 0.049, p=0.04\right.$; Cohen's $\left.f^{2}=0.03\right)$.

In high-income neighborhoods, no significant interactions and main effects were found in the multivariate model (Table 4).

\section{Discussion}

The main aim of this study was to investigate if psychosocial factors moderate the association between walkability and different domains of children's PA. Furthermore, main effects of psychosocial factors on children's PA were investigated.
Few interactions between neighborhood walkability and psychosocial factors were found in relation to different domains of PA. In total, only 7 out of 42 investigated interactions were significant and 3 of these interactions were only significant in low-income neighborhoods. Only 4 out of 42 interactions were significant in both high- and low-income neighborhoods. Besides, the effect sizes of these interactions were very small. This indicates that in general, there is no strong interaction between psychosocial factors and walkability in relation to children's PA and in general, the hypothesis (i.e. that walkability would be more strongly related to PA among children with a negative psychosocial profile, whereas among children with a positive psychosocial profile walkability would be less important to explain PA) could not be not confirmed, as only few interactions in different directions were found. The lack of interactions between objective walkability and psychosocial factors in relation to children's PA indicates that changing the objective walkability of a neighborhood might affect PA levels of children with positive versus negative psychosocial profiles in the same way. This was also found among Belgian older adults [26].

The hypothesis, based on a study among Belgian adolescents, that walkability would be more strongly related to PA among children with negative psychosocial profiles and that PA levels of children with a positive psychosocial profile would be high, irrespective of the neighborhood walkability, was only confirmed for 2 interactions among children living in low-income neighborhoods. Effect sizes of these interactions were small. Children living in low-income neighborhoods with lower parental attitude and lower friend support, engaged more in active transportation (+2 min/day) and in more MVPA on week days $(+18 \mathrm{~min} /$ day $)$ respectively, when they lived in a neighborhood with high walkability, compared to children living in low walkable neighborhoods. For children living in low-income neighborhoods, with higher friend support and a better parental attitude toward PA, walkability did not explain their PA. This shows that children who are at risk for lower PA levels, due to a lower SES [51] and a lower parental attitude and less friend support, would benefit the most of an increase in neighborhood walkability. However, these findings need to be confirmed in future research.

Also interactions in the opposite direction of the hypothesis (i.e. walkability was more strongly related to PA among children with positive psychosocial profiles compared to children with more negative psychosocial profiles) were found, but effect sizes of these interactions were mostly very small (Cohen's $f^{2}<0.02$ ). Only in one interaction that was found in the opposite direction of the hypothesis, a small effect size was found (Cohen's $\mathrm{f}^{2}$ between 0.02 and 0.15). Among children with higher 
self-efficacy and living in low-income neighborhoods, a high walkable neighborhood accounted for 25 mins/day of MVPA per weekend day, whereas among children with a lower self-efficacy, walkability did not explain children's weekend MVPA.

The low number of significant interactions between psychosocial factors and walkability in relation to PA and the small effect sizes of the significant interactions demonstrate that walkability interventions may affect children with different psychosocial profiles in the same way. So, based on previous findings, it might be presumed that increasing walkability will lead to more walking for transportation among children living in lowincome neighborhoods. However, when walkability will be increased, it should be taken into account that this can also have negative effects on children's sport during leisure in low-income neighborhoods [17]. Therefore, increasing walkability should focus on the increase of walkability for cyclists and pedestrians, but not for motorized traffic to retain the safety of the neighborhood. This is important as a safe neighborhood is related to more PA $[7,52,53]$. This can be done by making small streets only accessible for cyclists and pedestrians, but not for motorized traffic or by installing footbridges or underpasses for cyclists on busy and dangerous roads to increase the walkability. Although effect sizes in the current study were small, changing the neighborhood can affect large groups of children at the same time, which may result in beneficial effects.

A second aim of this study was to determine the main effects of psychosocial factors on children's PA. Consistent main effects of psychosocial factors in relation to children's PA with small effect sizes were found. It is possible that these small effect sizes are due to the fact that psychosocial factors were parental reported instead of children's report. It is possible that larger effect sizes would have been found if children reported their psychosocial factors themselves. As expected, having a more positive psychosocial profile toward PA was related to more PA among children. The most important main effects were found in relation to children's sports during leisure. Self-efficacy and parental support were directly positively related to children's sports during leisure. Besides, although effect sizes were very small, parental support was also directly and positively related to cycling for transportation during leisure and self-efficacy was positively related to MVPA on weekdays. Furthermore, a direct and negative relation was found between perceived barriers and sports during leisure with a small effect size. This indicates that it might be valuable for parents living in high- and low-income neighborhoods and neighborhoods with high and low walkability to support their child to be physically active, by providing transportation to sports activities, by watching and cheering for their child during sports and by doing sports together. Furthermore, suggestions can be made to reduce barriers toward PA among children and to increase children's self-efficacy, as perceiving many barriers and having low self-efficacy is related to less sports during leisure time. This can be done by offering children easy-accessible and enjoyable sport activities in terms of timing, location, costs and level such as extracurricular school-based sports [54]. Sport clubs should also focus on non-competitive sports in order to decrease the barriers 'not liking sports' and not 'being good at sports'. Besides, children need to be made aware that they can be physically active, even if they have to get up early, if their friends want to do something else, if they have a lot of work for school and if PA is exhausting and difficult. Different behavior change techniques can be used to increase children's self-efficacy (e.g. prompt barrier identification, action planning,...[55]). However, effect sizes of psychosocial factors in relation to children's PA were small. Therefore, effects of changing these psychosocial factors are expected to be small, so changing psychosocial factors among children might not be the most ideal strategy to increase PA among children. In line with a review of previous studies [10], self-efficacy and parental support seem to be the two most important correlates of children's sports and MVPA. Interventions focusing on the increase of parental support and selfefficacy and the decrease of barriers toward PA could possibly have small effects on children's PA levels in high- and low-income neighborhoods and in neighborhoods with high or low walkability. Furthermore, future longitudinal research and intervention studies are necessary to confirm this hypothesis.

The relatively large sample, the combination of selfreported and objective assessment of children's PA and the objective assessment of neighborhood walkability were strengths of this study. A first limitation of the study is the cross-sectional design as no causal relationships could be examined. By using cross-sectional data, it is possible to interpret the interactions in the other direction: i.e. walkability as a moderator of the association between psychosocial factors and PA. However, in the current manuscript interactions were described as if psychosocial factors moderate the association between walkability and PA, based on previous research among other age groups. Besides, a large number of associations between different factors and different domains of PA were investigated, due to the fact that hypotheses about the inclusion of variables could not be made due to lack of previous research and models. Therefore, before constructing the final model, a large number of preliminary bivariate analyses were conducted. Based on these preliminary analyses, the variables in the final model were determined. However, by investigating a large number of 
associations in the preliminary analyses, the likelihood of incorrectly rejecting a null hypothesis increased. The Bonferroni method is a method to counteract this problem, by lowering the significance level of a test $(\alpha=\alpha / n$, with $\mathrm{n}=$ the number of tests). However, an important disadvantage of using the Bonferroni correction is that this method is very strict and only focuses on reducing type 1 errors but the chance for making type 2 errors increases [56]. Furthermore, these analyses were executed as preliminary analyses, and the number of analyses and determinants in the final models were limited. Therefore, the Bonferroni correction was not applied to the analyses.

Furthermore, in Ghent, more people live in high walkable, low-income neighborhoods $(n=157389)$ or low walkable, high income neighborhoods $(n=44809)$ compared to low walkable, low-income neighborhoods $(n=$ 9623) or high walkable, high income neighborhoods ( $n$ $=43733$ ). As children were recruited in schools instead of neighborhoods with varying walkability and income levels, this led to the inclusion of children living mostly in high-income, low walkable or low-income, high walkable neighborhoods; children living in low-income, low walkable and high-income, high walkable neighborhoods were underrepresented. So the division of children across the different neighborhoods in the current study represents the actual distribution of children living in these neighborhoods but this is a methodological weakness of the study. Besides, response rates of school principals were rather low, however this was comparable to prior studies [57] that were based on questionnaires for pupils and parents. The low response rate might be due to the fact that schools have many obligations and are consequently not very keen on spending time on research activities. It is possible that parents who attach more importance to PA could have been more willing to let their child participate in this study. Furthermore, psychosocial factors were formulated toward PA and sports in general and not toward specific domains of PA (e.g. walking for transportation during leisure). It is likely that the formulation of these factors toward active transportation would have resulted in more significant associations between these factors and domains of active transportation. Therefore, it is recommended for future research to formulate the psychosocial factors more specifically toward the domain of PA that is investigated. Psychosocial factors were also mainly questioned from the parents' viewpoint rather than from children's viewpoint. Parental report of psychosocial factors was used in previous studies with acceptable reliability [37, 38]. Furthermore, parental education was used as a proxy measure of family SES, as data on working or income status were unavailable in this study. Future research is necessary as it is likely that other factors also moderate the association between objective walkability and PA.

\section{Conclusions}

Only few interactions (7 out of 42), with very small effect sizes between objective neighborhood walkability and psychosocial characteristics were found in relation to children's PA in different directions. The hypothesis that walkability would be more strongly related to PA among children with more negative psychosocial profiles could not be confirmed. Increasing walkability for cyclists and pedestrians might be effective in increasing PA among children with positive and negative psychosocial profiles toward PA. In both high- and low-income neighborhoods, parental support and self-efficacy were positively related to children's sports and MVPA, independent of the level of walkability. Based on the results of this study, it seems that focusing on these specific psychosocial factors to increase PA can possibly be effective in both high- and low-walkable neighborhoods, as well as in high- and low-income neighborhoods, although the effects can be small.

\section{Additional file}

\section{Additional file 1: Supplementary material. (SAV $105 \mathrm{~kb}$ )}

\section{Abbreviations \\ ATS: Active transportation to school; BEPAS: Belgian Environmental Physical Activity Study; FPAQ: Flemish Physical Activity Questionnaire; \\ GIS: Geographical information system; MVPA: Moderate- to vigorous-intensity physical activity; PA: Physical activity; SES: Socio-economic status}

\section{Acknowledgments \\ SDH and DVD were supported by Research Foundation Flanders (FWO) (grant number: FWO12/ASP/102). The authors want to thank Tine Coolen, Eva D'Hoore, Gert Lambrecht, Sarah Minten, An-Sofie Pinket, Britt Van Oost and Lieve Vanoverschelde for their assistance in data collection.}

\section{Funding}

This research was supported by Research Foundation Flanders (FWO). The funding body had no role in the design of the study and collection, analysis, and interpretation of data and in writing the manuscript.

Availability of data and materials

The dataset supporting the conclusions of this article is included within the article and its Additional file 1.

\section{Authors' contributions}

All authors read and approved the final version of the manuscript. SDH coordinated the data collection, conducted the statistical analyses and drafted the manuscript. BD, GC, FG and IDB participated in the interpretation of the data, revised the draft versions of the manuscript and provided critical comments during the process.

\section{Competing interest}

The authors declare that they have no competing interests.

Consent for publication

Not applicable.

Ethics approval and consent to participate

The Ethics Committee of the Ghent University Hospital approved the study. Parental informed consent was obtained from all individual participants included in the study. 


\section{Author details}

${ }^{1}$ Faculty of Medicine and Health Sciences, Department of Movement and Sports Sciences, Ghent University, Watersportlaan 2, 9000 Ghent, Belgium. ${ }^{2}$ Research Foundation Flanders (FWO), Egmontstraat 5, Brussels 1000, Belgium. ${ }^{3}$ Department of Public Health, Ghent University, De Pintelaan 185, 9000 Ghent, Belgium. ${ }^{4}$ Department of Human Biometrics and Biomechanics, Vrije Universiteit Brussel, Brussels, Belgium.

\section{Received: 14 December 2015 Accepted: 24 November 2016 Published online: 09 December 2016}

\section{References}

1. Janssen I, Leblanc AG. Systematic review of the health benefits of physical activity and fitness in school-aged children and youth. Int J Behav Nutr Phys Act. 2010;7:40.

2. Verloigne $M$, Van Lippevelde $W$, Maes L, Yildirim M, Chinapaw M, Manios $Y$, et al. Levels of physical activity and sedentary time among 10- to 12-yearold boys and girls across 5 European countries using accelerometers: an observational study within the ENERGY-project. Int J Behav Nutr Phys Act. 2012:9:34.

3. Baranowski T, Anderson C, Carmack C. Mediating variable framework in physical activity interventions. How are we doing? How might we do better? Am J Prev Med. 1998;15:266-97.

4. Sallis JF, Owen N. Ecological models of health behavior. In: Glanz K, Rimer BK, Viswanath K, editors. Health behavior: theory, research, and practice. 5th ed. San Francisco: Jossey-Bass; 2015. p. 43-64.

5. Ding D, Sallis JF, Kerr J, Lee S, Rosenberg DE. Neighborhood environment and physical activity among youth a review. Am J Prev Med. 2011:41:44255 .

6. Pont K, Ziviani J, Wadley D, Bennett S, Abbott R. Environmental correlates of children's active transportation: a systematic literature review. Health Place. 2009; 15:827-40

7. Carver A, Timperio A, Crawford D. Playing it safe: the influence of neighbourhood safety on children's physical activity. A review. Health Place. 2008;14:217-27.

8. Panter JR, Jones AP, van Sluijs EMF. Environmental determinants of active travel in youth: A review and framework for future research. Int J Behav Nutr Phys Act 5.1. 2008:1.

9. Davison K, Lawson C. Do attributes in the physical environment influence children's physical activity? A review of the literature. Int J Behav Nutr Phys Act. 2006:3:19.

10. van der Horst K, Paw MJ, Twisk JW, Van Mechelen W. A brief review on correlates of physical activity and sedentariness in youth. Med Sci Sports Exerc. 2007:39:1241-50.

11. Sallis JF, Prochaska JJ, Taylor WC. A review of correlates of physical activity of children and adolescents. Med Sci Sports Exerc. 2000;32:963-75.

12. Saelens BE, Sallis JF, Frank LD. Environmental correlates of walking and cycling: findings from the transportation, urban design, and planning literatures. Ann Behav Med. 2003;25:80-91.

13. Kerr J, Rosenberg D, Sallis JF, Saelens BE, Frank LD, Conway TL. Active commuting to school: Associations with environment and parental concerns. Med Sci Sports Exerc. 2006;38:787-94.

14. Napier MA, Brown BB, Werner CM, Gallimore J. Walking to school: Community design and child and parent barriers. J Environ Psychol. 2011;31:45-51.

15. Christiansen LB, Toftager M, Schipperijn J, Ersboll AK, Giles-Corti B, Troelsen J. School site walkability and active school transport - association, mediation and moderation. J Transp Geogr. 2014;34:7-15.

16. Trapp GS, Giles-Corti B, Christian HE, Bulsara M, Timperio AF, McCormack GR, et al. On your bike! a cross-sectional study of the individual, social and environmental correlates of cycling to school. Int J Behav Nutr Phys Act. 2011:8:123.

17. D'Haese S, Van Dyck D, De Bourdeaudhuij I, Deforche B, Cardon G. The association between objective walkability, neighborhood socio-economic status, and physical activity in Belgian children. Int J Behav Nutr Phys Act. 2014;11:104

18. Sallis JF, Saelens BE, Frank LD, Conway TL, Slymen DJ, Cain KL, et al. Neighborhood built environment and income: examining multiple health outcomes. Soc Sci Med. 2009:68:1285-93.

19. Van Dyck D, Cardon G, Deforche B, Sallis JF, Owen N, De Bourdeaudhuij I. Neighborhood SES and walkability are related to physical activity behavior in Belgian adults. Prev Med. 2010;50 Suppl 1:S74-9.
20. Owen N, Cerin E, Leslie E, duToit L, Coffee N, Frank LD, et al. Neighborhood walkability and the walking behavior of Australian adults. Am J Prev Med. 2007:33:387-95

21. Sundquist K, Eriksson U, Kawakami N, Skog L, Ohlsson H, Arvidsson D. Neighborhood walkability, physical activity, and walking behavior: the Swedish Neighborhood and Physical Activity (SNAP) study. Soc Sci Med. 2011;72:1266-73.

22. De Meester F, Van Dyck D, De Bourdeaudhuij I, Deforche B, Cardon G. Do psychosocial factors moderate the association between neighborhood walkability and adolescents' physical activity? Soc Sci Med. 2013:81:1-9.

23. Kaczynski AT, Robertson-Wilson J, Decloe M. Interaction of perceived neighborhood walkability and self-efficacy on physical activity. J Phys Act Health. 2012;9:208-17

24. Van Dyck D, Deforche B, Cardon G, De Bourdeaudhuij I. Neighbourhood walkability and its particular importance for adults with a preference for passive transport. Health Place. 2009;15:496-504.

25. Carlson JA, Sallis JF, Conway TL, Saelens BE, Frank LD, Kerr J, et al. Interactions between psychosocial and built environment factors in explaining older adults' physical activity. Prev Med. 2012:54:68-73

26. Van Holle V, Van Cauwenberg J, Deforche B, Van de Weghe N, De Bourdeaudhuij I, Van Dyck D. Do psychosocial factors moderate the association between objective neighborhood walkability and older adults' physical activity? Health Place. 2015;34:118-25.

27. Shavers VL. Measurement of socioeconomic status in health disparities research. J Natl Med Assoc. 2007:99:1013-23.

28. Troiano RP, McClain JJ, Brychta RJ, Chen KY. Evolution of accelerometer methods for physical activity research. Br J Sports Med. 2014;48:1019-23.

29. Robusto KM, Trost SG. Comparison of three generations of ActiGraph activity monitors in children and adolescents. J Sports Sci. 2012;30:1429-35.

30. Treuth MS, Sherwood NE, Butte NF, McClanahan B, Obarzanek E, Zhou A, et al. Validity and reliability of activity measures in African-American girls for GEMS. Med Sci Sports Exerc. 2003:35:532-9.

31. Stevens J, Murray DM, Baggett CD, Elder JP, Lohman TG, Lytle LA, et al. Objectively assessed associations between physical activity and body composition in middle-school girls: the Trial of Activity for Adolescent Girls. Am J Epidemiol. 2007:166:1298-305.

32. De Meester F, De Bourdeaudhuij I, Deforche B, Ottevaere C, Cardon G. Measuring physical activity using accelerometry in 13-15-year-old adolescents: the importance of including non-wear activities. Public Health Nutr. 2011;14:2124-33.

33. Evenson KR, Catellier DJ, Gill K, Ondrak KS, McMurray RG. Calibration of two objective measures of physical activity for children. J Sports Sci. 2008;26: 1557-65.

34. Trost SG, Loprinzi PD, Moore R, Pfeiffer KA. Comparison of accelerometer cut points for predicting activity intensity in youth. Med Sci Sports Exerc. 2011:43:1360-8.

35. Mattocks C, Ness A, Leary S, Tilling K, Blair SN, Shield J, et al. Use of accelerometers in a large field-based study of children: protocols, design issues, and effects on precision. J Phys Act Health. 2008;5 Suppl 1:S98-111.

36. Verstraete S, De Bourdeaudhuij I, Cardon G. Validation of a physical activity questionnaire for children. Medicine and Science in Sports and Exercise 5, S337. 2003. Ref Type: Abstract

37. Frank LD, Sallis JF, Saelens BE, Leary L, Cain K, Conway TL, et al. The development of a walkability index: application to the Neighborhood Quality of Life Study. Br J Sports Med. 2010;44:924-33.

38. Bourdeaudhuij I, Lefevre J, Deforche B, Wijndaele K, Matton L, Philippaerts R. Physical activity and psychosocial correlates in normal weight and overweight 11 to 19 year olds. Obes Res. 2005;13:1097-105.

39. De Bourdeaudhuij I, Teixeira PJ, Cardon G, Deforche B. Environmental and psychosocial correlates of physical activity in Portuguese and Belgian adults. Public Health Nutr. 2005;8:886-95.

40. Deforche B, De Bourdeaudhuij I, Tanghe A, Hills AP, De Bode P. Changes in physical activity and psychosocial determinants of physical activity in children and adolescents treated for obesity. Patient Educ Couns. 2004:55: 407-15

41. Van Dyck D, Cardon G, Deforche B, Giles-Corti B, Sallis JF, Owen N, et al. Environmental and psychosocial correlates of accelerometer-assessed and self-reported physical activity in Belgian adults. Int J Behav Med. 2011;18: 235-45. 
42. Van Dyck D, De Bourdeaudhuij I, Deliens T, Deforche B. Can Changes in Psychosocial Factors and Residency Explain the Decrease in Physical Activity During the Transition from High School to College or University? Int J Behav Med. 2014;22(2):178-186.

43. de Vries H, Dijkstra M, Kuhlman P. Self-efficacy: the third factor besides attitude and subjective norm as a predictor of behavioural intentions. Health Educ Res. 1988:3:273-82.

44. De Bourdeaudhuij I, Sallis J. Relative contribution of psychosocial variables to the explanation of physical activity in three population-based adult samples. Prev Med. 2002;34:279-88.

45. De Bourdeaudhuij I, Van Oost P, Mommerency G. Psychological determinants of leisure time physical activity in adolescents and adults. Belgium: Ghent University; 1994. Ref Type: Report.

46. Browne WJ. MCMC Estimation in MLwiN v2.1. Centre for Multilevel Modelling. Bristol: University of Bristol. 2009.

47. Rasbash J, Charlton C, Jones K, Pillinger R. Manual supplement for MLwiN Version 2.14. Bristol: University of Bristol; 2009.

48. Selya AS, Rose JS, Dierker LC, Hedeker D, Mermelstein RJ. A practical guide to calculating Cohen's f(2), a measure of local effect size, from PROC MIXED. Front Psychol. 2012;3:111.

49. Cohen J. Statistical power analysis for the behavioral sciences. USA: Academic press; 2013.

50. Twisk J. Applied multilevel analysis. Cambridge: Cambridge University Press; 2006.

51. Sterdt E, Liersch S, Walter U. Correlates of physical activity of children and adolescents: A systematic review of reviews. Health Educ Res. 2013;73(1): 72-89.

52. D'Haese S, Van Dyck D, De Bourdeaudhuij I, Deforche B, Cardon G. The association between the parental perception of the physical neighborhood environment and children's location-specific physical activity. BMC Public Health. 2015;15:565.

53. Veitch J, Salmon J, Ball K. Individual, social and physical environmental correlates of children's active free-play: a cross-sectional study. Int J Behav Nutr Phys Act. 2010;7:11.

54. De Meester A, Aelterman N, Cardon G, De Bourdeaudhuij I, Haerens L. Extracurricular school-based sports as a motivating vehicle for sports participation in youth: a cross-sectional study. Int J Behav Nutr Phys Act. 2014;11:48.

55. Michie S, Ashford S, Sniehotta FF, Dombrowski SU, Bishop A, French DP. A refined taxonomy of behaviour change techniques to help people change their physical activity and healthy eating behaviours: the CALO-RE taxonomy. Psychological Health. 2011;26:1479-98.

56. Perneger TV. What's wrong with Bonferroni adjustments. BMJ. 1998; 316(7139):1236-8.

57. D'Haese S, De Meester F, De Bourdeaudhuij I, Deforche B, Cardon G. Criterion distances and environmental correlates of active commuting to school in children. Int J Behav Nutr Phys Act. 2011;8:88

\section{Submit your next manuscript to BioMed Central and we will help you at every step:}

- We accept pre-submission inquiries

- Our selector tool helps you to find the most relevant journal

- We provide round the clock customer support

- Convenient online submission

- Thorough peer review

- Inclusion in PubMed and all major indexing services

- Maximum visibility for your research

Submit your manuscript at www.biomedcentral.com/submit
Biomed Central 